\title{
Scleral buckling with a noncontact wide-angle viewing system in the management of retinal detachment with undetected retinal break:
}

\section{a case report}

Mihori Kita

Yukiko Fujii

Naoaki Kawagoe

Sachiyo Hama

Department of Ophthalmology, National Hospital Organization Kyoto Medical Center, Kyoto, Japan

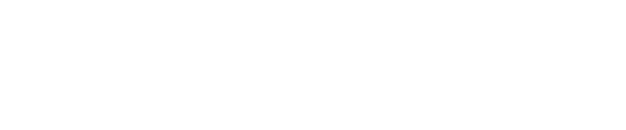

Abstract: A young patient who showed rhegmatogenous retinal detachment with preoperatively undetected retinal break was successfully treated by scleral buckling using a noncontact wide-angle viewing system.

Keywords: retinal detachment, retinal breaks, scleral buckling, noncontact wide-angle viewing system

\section{Introduction}

Traditionally, rhegmatogenous retinal detachments with undetectable breaks have been managed using circumferential buckling and cryopexy of suspicious areas, providing a success rate of $53 \%-85 \% .^{1-5}$ Recently, the effectiveness of primary pars plana vitrectomy or combined pars plana vitrectomy and scleral buckling procedures has been reported. ${ }^{6-8}$ It has been reported that endoscope-assisted vitrectomy seems promising in the management of pseudophakic and aphakic retinal detachments with undetected retinal breaks because of the ability to diagnose retinal breaks. ${ }^{9}$

Here, the case of a young phakic patient who presented showing rhegmatogenous retinal detachment with an undetected retinal break preoperatively and was successfully treated with scleral buckling using a noncontact wide-angle viewing system is reported.

\section{Case presentation}

A 16-year-old Japanese boy was referred to the authors' clinic with retinal detachment of the right eye. At the time of the first visit to the clinic, the best corrected visual acuity was 0.7 , with myopia of $9 \mathrm{D}$ in the right eye. Axial length was $26.95 \mathrm{~mm}$. Intraocular pressure was within the normal range. Slit-lamp examination revealed intact anterior segments.

Fundus examination showed retinal detachment in the two inferior quadrants associated with multiple lattice degenerations and subretinal strands in the right eye. Despite careful fundus examination, retinal breaks could not be identified. The macula remained attached in the right eye. The patient had no history of trauma or atopy.

The patient subsequently underwent repair of the retinal detachment in the right eye with scleral buckling procedure using a noncontact wide-angle viewing system.
Correspondence: Mihori Kita

Department of Ophthalmology, National Hospital Organization Kyoto Medical Center, I-I Mukouhata-cho, Fukakusa, Fushimi-ku, Kyoto 6|2-8555, Japan

$\mathrm{Tel}+8|7564| 9|6|$

Fax+8I 756434325

Email mihorik@kuhp.kyoto-u.ac.jp 


\section{Surgical procedures for the right eye}

Following conjunctival peritomy 360 degrees around the limbus, four rectus muscles were isolated for encircling buckling. A trocar for a 25-gauge light fiber (Alcon Laboratories, Fort Worth, TX, USA) was placed $4.0 \mathrm{~mm}$ behind the limbus at the 8 o'clock position. The noncontact wide-angle viewing system (Resight ${ }^{\mathrm{TM}}$; Carl Zeiss Meditec AG, Jena, Germany) was activated after the light fiber was inserted through the trocar and the light was turned on.

Dynamic scleral compression with a cryoprobe was performed to identify the retinal breaks. A tiny retinal hole was found at the 4 o'clock position (Figure 1). The retinopexy with cryopexy and diathermy to the break and to the area of lattice degeneration was applied.

After the light fiber was pulled off and a plug was inserted into the trocar, the encircling buckling procedure using a silicone tire and belt (numbers 277, 240, and 270; MIRA Inc, Waltham, MA, USA) and external drainage of subretinal fluid through the sclerotomy at the 5 o'clock position were performed under the surgical microscope. The fundus was checked, if necessary, under panoramic view using the noncontact wide-angle viewing system with 25 -gauge light fiber during surgery.

No intra- or postoperative complications were encountered. At the 6-month follow-up, the retina remained attached, and best corrected visual acuity was 0.9 in the right eye. The lens showed neither subcapsular opacity nor nuclear sclerosis.

\section{Discussion}

In rhegmatogenous retinal detachments, one of the prognostic factors for poor surgical outcomes is the inability to detect

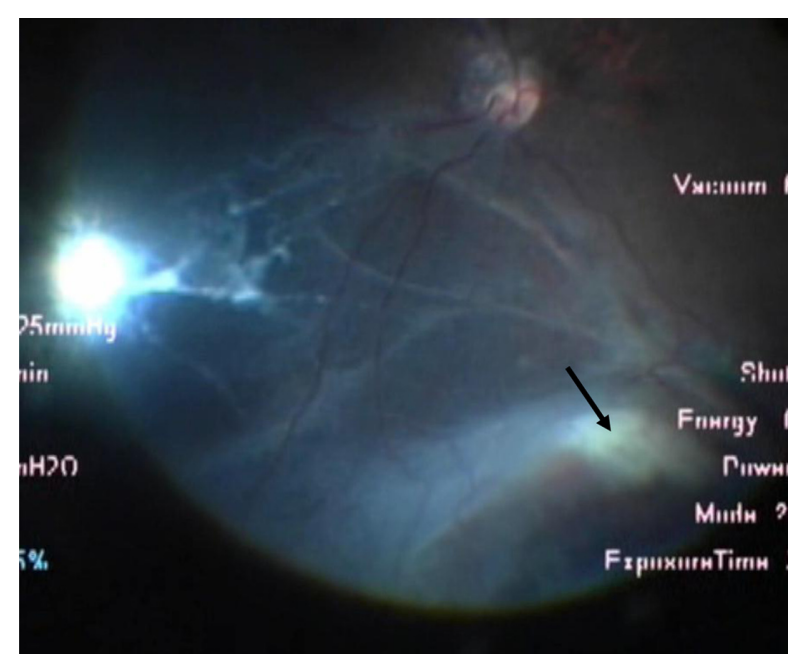

Figure I Intraoperative view using the wide-angle viewing system. Note: A tiny retinal break is apparent (arrow). retinal breaks. Various strategies, including endoscopicassisted vitrectomy, have been proposed to manage retinal detachments without detected breaks preoperatively. . $3,3-13^{-13}$

Traditionally, scleral buckling has been considered the procedure of choice for rhegmatogenous retinal detachment in young patients. During scleral buckling procedures, visualization of the fundus is performed using an indirect ophthalmoscope. The image is inverted and small, and cannot be readily shared with medical staff, representing a disadvantage for identifying tiny retinal breaks.

Recently, use of a wide-angle viewing system in vitrectomy surgery has become popular, as this option can easily provide a panoramic view of the surgical field. Two types of the wide-angle viewing system exist, with both contact and noncontact types available. The noncontact type is more popular because of the stability of the image against the tilt of the eyeball and the ease of manipulation. A few reports demonstrated that simultaneous use of a noncontact wide-angle viewing system combined with light fiber illumination for fundus visualization is also feasible for scleral buckling procedures for retinal detachment with preoperatively detected retinal breaks. ${ }^{14,15}$ The advantages of this method are that the clear images of the retina are directed through the surgical microscope, and can thus be enlarged and seen even with the small pupil. This allows easier detection of retinal breaks using dynamic scleral compression with a cryoprobe under the wide-angle viewing system. In this system, all procedures of scleral buckling can be performed under surgical microscopy, improving the ease of operation for surgeons with refractive errors, especially presbyopia. Images of the fundus can be shared during retinopexy, which will undoubtedly prove useful in surgical education.

Caution should be taken due to the possible risks of surgical complications including vitreous wick from the scleral wound, endophthalmitis, lens damage, and light toxicity. The smaller gauge fiber illumination could be ideal for preventing complications.

\section{Conclusion}

Scleral buckling with a noncontact wide-angle viewing system seems promising for the management of rhegmatogenous retinal detachments, not only with preoperatively detected retinal breaks but also those with undetected retinal breaks.

\section{Disclosure}

The authors report no conflicts of interest in this work. 


\section{References}

1. Norton EW. Retinal detachment in aphakia. Am J Ophthalmol. 1964;58:111-124.

2. Griffith RD, Ryan EA, Hilton GF. Primary retinal detachments without apparent breaks. Am J Ophthalmol. 1976;81(4):420-427.

3. Wong D, Billington BM, Chignell AH. Pars plana vitrectomy for retinal detachment with unseen retinal holes. Graefes Arch Clin Exp Ophthalmol. 1987;225(4):269-271.

4. Criswick VG, Brockhurst RJ. Retinal detachment. 360 degree scleral buckling as a primary procedure. Arch Ophthalmol. 1969;82(5):641-650.

5. Grizzard WS, Hilton GF, Hammer ME, Taren D. A multivariate analysis of anatomic success of retinal detachments treated with scleral buckling. Graefes Arch Clin Exp Ophthalmol. 1994;232(1):1-7.

6. Devenyi RG, de Carvalho Nakamura H. Combined scleral buckle and pars plana vitrectomy as a primary procedure for pseudophakic retinal detachments. Ophthalmic Surg Lasers. 1999;30(8):615-618.

7. Brazitikos PD, D’Amico DJ, Tsinopoulos IT, Stangos NT. Primary vitrectomy with perfluoro-n-octane use in the treatment of pseudophakic retinal detachment with undetected retinal breaks. Retina. 1999;19(2):103-109.

8. Rosen PH, Wong HC, McLeod D. Indentation microsurgery: internal searching for retinal breaks. Eye (Lond). 1989;3(Pt 3):277-281.

9. Kita M, Yoshimura N. Endoscope-assisted vitrectomy in the management of pseudophakic and aphakic retinal detachments with undetected retinal breaks. Retina. 2011;31(7):1347-1351.
10. Tewari HK, Kedar S, Kumar A, Garg SP, Verma LK. Comparison of scleral buckling with combined scleral buckling and pars plana vitrectomy in the management of rhegmatogenous retinal detachment with unseen retinal breaks. Clin Experiment Ophthalmol. 2003; 31(5):403-407.

11. Salicone A, Smiddy WE, Venkatraman A, Feuer W. Management of retinal detachment when no break is found. Ophthalmology. 2006; 113(3):398-403.

12. Jackson TL, Kwan AS, Laidlaw AH, Aylward W. Identification of retinal breaks using subretinal trypan blue injection. Ophthalmology. 2007;114(3):587-590.

13. Wong R, Gupta B, Aylward GW, Laidlaw DA. Dye extrusion technique (DE-TECH): occult retinal break detection with subretinal dye extrusion during vitrectomy for retinal detachment repair. Retina. 2009;29(4):492-496.

14. Aras C, Ucar D, Koytak A, Yetik H. Scleral buckling with a noncontact wide-angle viewing system. Ophthalmologica. 2012; 227(2):107-110.

15. Shiba H, Shiba T, Kodaka R, Kamizuru M, Shiba K. Retinal reattachment surgery using wide-angle viewing systems and chandelier illumination. Folia Japonica de Ophthalmologica Clinica. 2010;23(2):301-304. Japanese.
Clinical Ophthalmology

\section{Publish your work in this journal}

Clinical Ophthalmology is an international, peer-reviewed journal covering all subspecialties within ophthalmology. Key topics include: Optometry; Visual science; Pharmacology and drug therapy in eye diseases; Basic Sciences; Primary and Secondary eye care; Patient Safety and Quality of Care Improvements. This journal is indexed on

Submit your manuscript here: http://www.dovepress.com/clinical-ophthalmology-journal

\section{Dovepress}

PubMed Central and CAS, and is the official journal of The Society of Clinical Ophthalmology (SCO). The manuscript management system is completely online and includes a very quick and fair peer-review system, which is all easy to use. Visit http://www.dovepress.com/ testimonials.php to read real quotes from published authors. 